
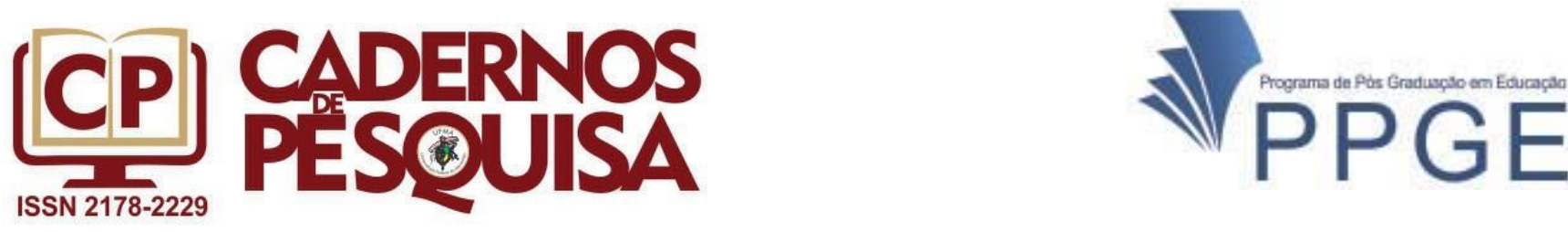

\title{
A Extensão Universitária: espaço de comunicação e de transformação social
}

\author{
University Outreach Work: space for communication and \\ social transformation
}

\section{Extensión Universitaria: espacio de comunicación y transformación social}

\author{
laned da Luz Sousa ${ }^{1}$ \\ ORCID: http://orcid.org/0000-0001-7262-0696
}

\author{
Rosária Helena Ruiz Nakashima ${ }^{2}$ \\ ORCID: http://orcid.org/0000-0001-7798-6363 \\ Jutta Gutberlett ${ }^{3}$ \\ ORCID: http://orcid.org/0000-0003-4602-1483
}

Resumo: Este artigo problematiza a relação da extensão universitária dialógica e emancipatória com as metodologias participativas, no contexto atual do ensino superior público, a partir da análise de três ações extensionistas, realizadas na Universidade Federal do Tocantins (UFT), Câmpus de Araguaína. Esta pesquisa ancora-se, metodologicamente, na análise qualitativa, com triangulação de pesquisa documental, entrevistas com docentes e relatório do Sistema de Informação e Gestão de Projetos (SIGProj). Tais ações evidenciaram caminhos para a materialização da comunicação entre universidade pública e sociedade que, comprometida com a inclusão social pela educação, poderá promover a (co)produção, o compartilhamento, a comunicação, as trocas e a integração de culturas na sociedade. As experiências extensionistas analisadas demonstraram que a universidade poderá ampliar a construção de conhecimentos socialmente relevantes e de transformação social pela ação, a partir da aprendizagem colaborativa entre agentes da Comissão Pastoral da Terra (CPT), acadêmicos, camponeses do Quilombo Grotão, docentes da universidade, grafiteiros, servidores técnico-administrativos estudantes da Educação Básica, professores das escolas rurais e de pequenas cidades, moradores de povoados e de comunidades rurais. Conclui-se que, apesar dos desafios atuais da universidade pública, algumas estratégias desenvolvidas demonstraram possibilidades de diálogos socioculturais, fortalecidos pela participação daqueles que estão fora da academia, reconhecidos como importantes coprodutores no processo de construção de saberes.

Palavras-chave: Extensão universitária. Metodologias participativas. Educação emancipatória.

Abstract: This article problematizes the relationship between dialogical and emancipatory university outreach work applying participatory methodologies, in the current context of public higher education, based on the analysis of three outreach actions, carried out at the Federal University of Tocantins,

\footnotetext{
${ }^{1}$ Mestra em Estudos de Cultura e Território pela Universidade Federal do Tocantins (UFT). Técnica em Assuntos Educacionais na Universidade Federal do Tocantins (UFT). Araguaína, Tocantins, Brasil. E-mail: ianed@uft.edu.br

${ }^{2}$ Doutora em Educação pela Universidade de São Paulo (USP). Professora Adjunta do curso de Licenciatura em História. Docente do Programa de Pós-Graduação em Estudos de Cultura e Território (PPGCult) na Universidade Federal do Tocantins (UFT), Tocantins, Brasil. E-mail: rosaria@uft.edu.br

${ }^{3}$ Professora Doutora de Geografia Humana na Universidade de Victoria, Colúmbia Britânica, Canadá. E-mail: gutber@uvic.ca
} 
Araguaína campus. This research is methodologically anchored in qualitative analysis with triangulation of documentary analysis, interviews with professors and the analysis of the Information and Project Management System reports. Such actions evidenced pathways for concrete communication between public universities and society, committed to social inclusion through education that promotes (co-)production, sharing, communication, exchanges and cultural integration in society. The outreach experiences analyzed showed that the university will be able to expand the construction of socially relevant knowledge and social transformation through actions based on collaborative learning among agents involving members from the Pastoral Land Commission (CPT), academics, peasants from the Quilombo Grotão community, graffiti artists, technical-administrative servants, students enrolled in basic education, teachers from rural schools and small towns, as well as residents from villages and rural communities. We conclude that, despite the current challenges of the public university, some strategies developed in te case studies demonstrated possibilities for sociocultural dialogue, strengthened by the participation of those who are outside the academy and are recognized as important co-producers in the process of building knowledge.

Keywords: University outreach work. Participatory methodologies. Emancipatory education.

Resúmen: Este artículo problematiza la relación entre la extensión universitaria dialógica y emancipadora con metodologías participativas, en el contexto actual de la educación superior pública, basada en el análisis de tres acciones de extensión, realizadas en la Universidad Federal de Tocantins, Câmpus de Araguaína. Esta investigación está anclada, metodológicamente, en análisis cualitativo, con triangulación de investigación documental, entrevistas con profesores e informes del Sistema de Información y Gestión de Proyectos. Dichas acciones evidenciaron caminos para la materialización de la comunicación entre las universidades públicas y la sociedad que, comprometidos con la inclusión social a través de la educación, pueden promover (co) producción, intercambio, comunicación, intercambios e integración de las culturas en la sociedad. Las experiencias de extensión analizadas mostraron que la universidad podrá expandir la construcción de conocimiento socialmente relevante y la transformación social a través de la acción, basada en el aprendizaje colaborativo entre agentes de la Comisión de Tierras Pastorales, académicos, campesinos de Quilombo Grotão, profesores universitarios, artistas de graffiti, servidores técnicosadministrativos, estudiantes de educación básica, maestros de escuelas rurales y pequeñas ciudades, residentes de aldeas y comunidades rurales. Se concluye que, a pesar de los desafíos actuales de la universidad pública, algunas estrategias desarrolladas demostraron posibilidades de diálogos socioculturales, fortalecidos por la participación de aquellos que están fuera de la academia, reconocidos como coproductores importantes en el proceso de construcción de conocimiento.

Palabras clave: Extensión Universitariav. Metodologías participativas. Educación emancipadora.

\section{INTRODUÇÃO}

Este artigo apresenta discussões sobre o papel das metodologias participativas (STRECK; ADMAS, 2014), como caminhos para o diálogo cultural e social, bem como para a construção de conhecimentos solidários. Compreendemos que as metodologias de pesquisa, de cunho participativo, foram mais coerentes neste processo de comunicação entre a universidade e a sociedade, na medida em que reconhecem os sujeitos/interlocutores como produtores de conhecimentos, isto é, não consideram apenas o protagonismo do pesquisador e suas metodologias científicas, mas valorizam um processo dinâmico de aprendizagem entre ambos. Para Streck e Admas (2014, p. 47), "o processo participativo na dinâmica da pesquisa estimula a postura de sujeitos ativos reconhecendo e reforçando seu papel 
protagonista na produção do espaço sociocultural, onde o conhecimento já não busca mais a certeza, mas a criatividade".

Reconhecemos também a importância do tripé universitário, composto por ensino, pesquisa e extensão, previsto no artigo 207 da Constituição brasileira de 1988, para a construção de uma relação que possibilita o encontro da comunidade acadêmica com a sociedade, a saber: "As universidades gozam de autonomia didático-cientifica, administrativa e de gestão financeira e patrimonial, e obedecerão ao princípio da indissociabilidade entre ensino, pesquisa e extensão" (BRASIL, 1988, p. 160).

Logo, este artigo defende a extensão como promotora de diálogo com a sociedade, em busca de uma educação emancipatória e comprometida com a inclusão social. Segundo Giatti (2020, p. 31, tradução nossa), "o verdadeiro engajamento para enfrentar a exclusão cognitiva convencional deve ser construído em processos dialógico de interações, promovendo confiança, reciprocidade, comprometimento e aprendizado social por meio de processos de orientação participativa".

Compreendemos a extensão à luz do pensamento de Paulo Freire, que nega o termo extensão pois, "[...] as conotações do que fazer verdadeiramente educativo, [...] se encontram no conceito de comunicação" (FREIRE, 2017a, p. 98). Para Freire, em qualquer setor, a ação do extensionista, parece considerar inferior quem recebe suas técnicas e por isso mesmo procura uma maneira de deixá-lo semelhante ao seu mundo. 'Daí que, em seu 'campo associativo', o termo 'extensão' [...] significa [...] transmissão, entrega, doação, messianismo, mecanicismo, invasão cultural, manipulação etc. (Ibid., p. 20)". Por tudo isso, o autor critica o termo extensão, já que de acordo com ele "[...] não corresponde um quefazer educativo libertador" (p. 21), isto é, para Freire, a tarefa do educador "corresponde ao conceito de comunicação, não ao de extensão" (p. 23).

Destacamos também, a importância da interdisciplinaridade, como promotora de um diálogo solidário entre os saberes e a forte relação da universidade com a (co)produção, o compartilhamento, a comunicação, as trocas e a integração de culturas, por meio de ações extensionistas. Compreendemos a cultura na perceptiva freireana, como criação transformadora da condição humana, também em conformidade com Hall (2016), a partir do compartilhamento de sentidos e 
significados por meio da linguagem. Em outras palavras, nas práticas sociais "[...] os significados culturais não estão somente na nossa cabeça - eles organizam e regulam práticas sociais, influenciam nossa conduta e consequentemente geram efeitos reais e práticos" (HALL, 2016, p. 20).

Assim, para a negociação de significados culturais, o diálogo se torna fundamental ao fortalecer a parceria universidade-sociedade e suas práticas culturais, em busca da valorização dos saberes não-acadêmicos, condizentes com a defesa de sua autonomia didático-científica e a inclusão social. Na acepção deste texto, o compromisso deve ser com a democratização do saber para "diminuir a distância entre universidade ou o que se faz nela e as classes populares, mas sem a perda da seriedade e do rigor. Sem negligenciar diante do dever de ensinar e de pesquisar" (FREIRE, 2015, p. 211). Portanto, entendemos que esse processo pode se efetivar por meio de processos participativos, que visem à autonomia dos sujeitos envolvidos.

\section{ASPECTOS METODOLÓGICOS}

Esta pesquisa pautou-se na abordagem qualitativa, de cunho exploratóriodescritivo, a partir da triangulação da pesquisa documental; análise das ações extensionistas, inspiradas em metodologias participativas (STRECK; ADMAS, 2014); e entrevistas com três docentes, coordenadores dessas ações. Estas foram selecionados a partir de dados públicos disponíveis no Sistema de Informação e Gestão de Projetos (SIGproj), com recorte para as ações de extensão desenvolvidas de janeiro de 2013 a junho de 2018, nos cursos de licenciatura em Letras, História e Geografia.

Entendemos a pesquisa como um processo de trocas com o outro que, segundo Brandão e Streck (2006, p. 13) é, antes de tudo, "uma pedagogia de criação solidária de saberes em que a palavra-chave não é o próprio 'conhecimento', mas é, antes dele, o 'diálogo'”. Ainda sobre o papel da pesquisa qualitativa e a função reflexiva do pesquisador, como "sujeito ativo da investigação científica", Gutberlet e Pontuschka (2010, p. 218) apontam para a necessidade de "[...] criar um ambiente que favoreça atitudes colaborativas e solidárias, um espaço onde as pessoas possam apoiar-se, ajudar-se e aprender de forma interativa no decorrer das atividades". 
A presente pesquisa foi realizada na Universidade Federal do Tocantins (UFT), especificamente no Câmpus de Araguaína. A UFT tem atualmente sete campi universitários, e o lócus desta pesquisa está situado no norte do estado do Tocantins, totalizando 232 docentes, 142 técnicos administrativos e 3.115 alunos , ofertando quatorze cursos de graduação e sete programas de pós-graduação.

Nesta pesquisa dialogamos com autores de diferentes áreas, tais como: Sociologia, Geografia, Pedagogia, Filosofia e Letras, na busca de maior integração de conhecimentos e compreensão do fenômeno. Nesse sentido, estamos de acordo com Pombo (2005, p. 13):

\begin{abstract}
Sem interesse real por aquilo que o outro tem para dizer não se faz interdisciplinaridade. Só há interdisciplinaridade se somos capazes de partilhar o nosso pequeno domínio do saber, se temos a coragem necessária para abandonar o conforto da nossa linguagem técnica e para nos aventurarmos num domínio que é de todos e de que ninguém é proprietário exclusivo.
\end{abstract}

Logo, a partir de uma perspectiva interdisciplinar, discutiremos, a seguir, como ações de extensão participativas podem ser as fontes de criação de conhecimento emancipatório.

\title{
3 A EXTENSÃO NA UFT E A CARACTERIZAÇÃO DAS AÇÕES PESQUISADAS
}

A Lei de Diretrizes e Bases da Educação Nacional (LDB) 9394/96, em seu artigo 43, inciso VIII, traz que dentre as finalidades da educação superior está a de "[...] atuar em favor da universalização e do aprimoramento da educação básica, mediante a formação e a capacitação de profissionais, a realização de pesquisas pedagógicas e o desenvolvimento de atividades de extensão que aproximem os dois níveis escolares" (BRASIL, 2017, p. 33). Nesse sentido, a UFT propõe que, por meio da extensão:

a comunidade acadêmica encontra na sociedade a oportunidade de colocar em prática o conhecimento acadêmico. Além disso, no retorno à Universidade, docentes e discentes trazem um aprendizado que, submetido à reflexão teórica, é acrescido àquele conhecimento. (UFT, 2018, n.p.).

Segundo a Pró-Reitoria de Extensão, Cultura e Assuntos Comunitários (Proex), a UFT, "[...] busca consolidar o projeto da Universidade de interagir com os diversos grupos sociais de forma a contribuir para a construção de uma sociedade mais justa, democrática e solidária". Para isso, definiu três eixos principais: "promover a cidadania; apoiar a diversidade étnico-cultural; promover a arte e a cultura" (UFT, 2018, n.p.). 
Conforme já afirmamos, as ações pesquisadas foram desenvolvidas no âmbito de cursos de licenciatura (Geografia, História e Letras) das Ciências Humanas e Letras da UFT, no câmpus de Araguaína. Ao valorizar essas áreas do conhecimento, buscamos analisar como os docentes mobilizaram seus conhecimentos em projetos que promoveram a aproximação com a sociedade e que resultaram em experiências que contribuíram para transformações sociais.

Os interlocutores desta pesquisa são docentes ${ }^{4}$ responsáveis pelos projetos de extensão analisados, selecionados para entrevista ${ }^{5}$ por serem coordenadores desses projetos. Nos quadros 1, 2 e 3 apresentamos o resumo dos projetos que integraram esta pesquisa:

Quadro 1 - Ação de extensão de Ramos Júnior (2018)

\begin{tabular}{|l|l|}
\hline $\begin{array}{l}\text { Nome da ação de } \\
\text { extensão }\end{array}$ & $\begin{array}{l}\text { Construindo Saberes: Agricultura Familiar e Movimento } \\
\text { Agroecológico }\end{array}$ \\
\hline Coordenador & Dernival Venâncio Ramos Júnior \\
\hline Palavras-chaves & Saberes, Práticas Agroecológicas, Ecologia dos Saberes, Bem Viver \\
\hline Proposta & $\begin{array}{l}\text { Está vinculado ao Núcleo de Pesquisa e Extensão em Saberes e } \\
\text { Práticas Agroecológicas - NEUZA e visa consolidar-se como um } \\
\text { organismo integrante da Universidade Federal do Tocantins (UFT) e } \\
\text { a sociedade, pensando de forma integrativa em saberes e práticas } \\
\text { agroecológicas. Ele trabalha pela integração dos diversos saberes } \\
\text { acadêmicos e não-acadêmicos. As soluções e práticas } \\
\text { desenvolvidas são pensadas de maneira integrativas por acadêmicos } \\
\text { e membros da comunidade, mobilizando seus saberes, práticas e } \\
\text { repertório material, imaterial e socioambiental }\end{array}$ \\
\hline
\end{tabular}

Fonte: Dados da pesquisa, sistematizados a partir das informações do SIGproj (2018). (grifo nosso)

A ação de extensão "Construindo Saberes: Agricultura Familiar e Movimento Agroecológico" emerge a partir de experiências pessoal e acadêmica dos professores Dernival Venâncio Ramos Júnior - com a teoria decolonial e metodologias participativas - e da professora Kênia Gonçalves Costa - com trabalhos com a interculturalidade -, bem como a partir de diálogos com Comissão

\footnotetext{
${ }^{4}$ Dernival Venâncio Ramos Júnior- Bacharelado e Licenciatura em História pela Universidade Federal de Goiás (2002). Mestrado em História pela Universidade Federal de Goiás (2004). Doutorado em História pela Universidade de Brasília (2009). Pós-Doutorado pela University of Florida, Estados Unidos.

Eliane Cristina Testa- Licenciatura em Letras (Português/Inglês) pela Faculdade Estadual de Educação Ciências e Letras de Paranavaí. Mestrado em Letras pela Universidade Estadual de Londrina (2002). Doutorado em Comunicação e Semiótica (PUC/SP - 2015).

Eliseu Pereira de Brito- Bacharelado e Licenciatura em Geografia pela Universidade Federal do Tocantins. Mestrado em Geografia pela Universidade Federal da Grande Dourados. Doutorado em Geografia pela Universidade Federal de Goiás.

${ }^{5}$ Todos os envolvidos na pesquisa autorizaram a divulgação de seus nomes no TCLE.
} 
Pastoral da Terra $(\mathrm{CPT})^{6}$. Uma das motivações para a sua concepção foi o edital de agroecologia do Conselho Nacional de Desenvolvimento Científico e Tecnológico (CNPq), publicado em 2016.

Essa proposta foi aceita e o Núcleo de Pesquisa e Extensão em Saberes e Práticas Agroecológicas (NEUZA) foi criado para desenvolver atividades em comunidades tradicionais, com objetivo de integrar saberes acadêmicos com os das comunidades, por meio do plantio agroecológico. O mesmo é formado por docentes da universidade, acadêmicos e membros da CPT. Dentre suas atividades está o plantio de espécies nativas nas comunidades tradicionais, bem como ações de ensino, pesquisa e extensão integradas ao Programa de Pós-graduação em Cultura e Território, visando à formação e a produção do conhecimento intercultural. No momento desta pesquisa, a ação de extensão (Quadro 1) está sendo realizada em uma comunidade quilombola, chamada de Grotão, localizado no município de Filadélfia-TO, distante $70 \mathrm{~km}$ de Araguaína-TO. Sobre a comunidade, segundo Ramos Júnior (2019, no prelo):

\begin{abstract}
A comunidade é formada por dezenove famílias e cerca de sessenta pessoas que ali vivem. As lideranças têm desenvolvido um trabalho junto à comunidade buscando resgatar e fortalecer sua cultura, de modo constante, rememoram, em atividades realizadas, as impressões das festas tradicionais, tais como: a Festa de Santo Reis, de São Benedito, a Festa do Divino, São João, São Pedro, São Lázaro e a dança do "lindô", do samba e baião. Ocorre ainda um esforço para que a produção material tradicional se mantenha.
\end{abstract}

Observa-se que o projeto está de acordo com um dos princípios do Regulamento das Ações de Extensão da Universidade Federal do Tocantins (Resolução 08, de 14 de março de 2018), ou seja, "estabelecimento da interação de conhecimentos e inter-relação entre disciplinas, áreas de conhecimento e metodologias, como estratégia para atender as demandas da formação e demandas sociais por meio de um processo interdisciplinar" (UFT, 2018, n. p.).

Freire (2018, p. 261) ao discutir com reitores de universidades em Buenos Aires na Argentina, sobre as questões políticas e epistemológicas envolvidas na universidade, assinala que:

A decisão política, de caráter progressista, [...] de pôr-se a universidade a serviço também dos interesses populares é a necessária implicação, na prática, de uma compreensão crítica em torno de como se deve relacionar a

\footnotetext{
${ }^{6}$ Órgão da Conferência Nacional dos Bispos do Brasil, vinculado à Comissão Episcopal para o Serviço da Caridade, da Justiça e da Paz.
} 
ciência universitária com a consciência das classes populares. No fundo a relação entre saber popular, senso comum e conhecimento científico.

Portanto, a ação de extensão "Construindo Saberes: Agricultura Familiar e Movimento Agroecológico" contribui para o que Santos (2011) chama de "recuperação da legitimidade social" da universidade, uma vez que, entre os princípios que devem orientar a reforma da universidade pública, para o autor, estão a pesquisa-ação e a ecologia dos saberes, compreendidos como áreas prioritárias para tal.

Quadro 2 - Ação de extensão de Testa (2017)

\begin{tabular}{|l|l|}
\hline $\begin{array}{l}\text { Nome da ação de } \\
\text { extensão }\end{array}$ & Projeto Grafite: arte democrática \\
\hline Coordenadora & Eliane Cristina Testa (Lia Testa) \\
\hline Palavras-chaves & Grafite, arte, processo coletivo e colaborativo. \\
\hline Proposta & $\begin{array}{l}\text { Este projeto acredita que a linguagem do grafite possibilita a } \\
\text { junção de diferentes saberes, em processos colaborativos e } \\
\text { coletivos, assim como, o incentivo à cultura local/regional, uma } \\
\text { vez que, pode efetivar a apresentação da produção dos artistas } \\
\text { urbanos (dos grafiteiros da cidade de Araguaína) por meio de } \\
\text { exposições, workshops e oficinas. Acreditamos ainda que a } \\
\text { intervenção no espaço (muros, paredes e/ou outros suportes, } \\
\text { porventura) do Campus Cimba pode gerar diferentes relações de } \\
\text { afeto do acadêmico com a Universidade, uma vez que, esta nova } \\
\text { paisagem feita de arte, engendra um outro tipo de identificação do } \\
\text { jovem (ou da comunidade acadêmica) com o local de saber. } \\
\text { Assim, estes múltiplos afetos, pautados em diferentes } \\
\text { sensibilizações, o oriundos do próprio poder da arte e/ou da da } \\
\text { criação coletiva, ajudam a construir um campus universitário mais } \\
\text { vivo, humano, dinâmico, orgânico, democrático e artístico. }\end{array}$ \\
\hline
\end{tabular}

Fonte: Dados da pesquisa, sistematizados a partir das informações do SIGproj (2018). (grifo nosso)

O projeto "Grafite: arte democrática" surgiu da experiência da docente e poeta Lia Testa com a arte, contemplada também pela sua formação acadêmica. A partir do projeto, a docente procurou a Direção do Câmpus Universitário para apresentá-lo e foi realizada uma consulta ao Conselho Diretor do Câmpus (instância máxima de decisão local) e com o movimento estudantil (representando a comunidade acadêmica), a fim de autorizar as mudanças que seriam realizadas na paisagem institucional.

Para ajudar na compra dos materiais de pintura e no pagamento dos artistas foi necessário arrecadação de verba por meio de rifas e contribuições individuais de outros docentes. No dia da realização das pinturas, foi feita uma reunião inicial em que os grafiteiros apresentaram seus trabalhos artísticos para pessoas da comunidade que estavam presentes, acadêmicos e docentes do câmpus. Os 
grafiteiros explicaram a técnica e suas histórias de vida, com o objetivo de contextualizar o trabalho realizado e envolver os participantes; além disso, foram oferecidos pincéis e rolos para quem quisesse participar durante a ação extensionista.

Tal projeto também atende a outro princípio do mesmo Regulamento de Extensão, isto é, "atuação dialógica de maneira a estabelecer interlocução entre a UFT e demais setores da sociedade na promoção da troca de saberes" (UFT, 2018, p. 3), neste caso, entre acadêmicos e grafiteiros da cidade de Araguaína.

$\mathrm{Na}$ perspectiva do projeto de Testa (2017), Freire (2017b) defende a necessidade de reconhecer e assumir a identidade cultural do educando, como saber necessário à prática docente progressista, isto é, "assumir-se como ser social e histórico como ser pensante, comunicante, transformador, criador, realizador de sonhos [...] (p. 42)”. Nessa abordagem, a educação ganha sentido de prática cultural transformadora,

A questão da identidade cultural, de que fazem parte a dimensão individual e a de classe dos educandos cujo respeito é absolutamente fundamental na prática sua educativa progressista, é problema que não pode ser desprezado. Tem que ver diretamente com a assunção de nós por nós mesmos (Ibid., p. 42).

Portanto, essa ação de extensão passou a fazer parte da paisagem do Câmpus, contribuindo para maior identificação dos acadêmicos com a universidade, pois os grafiteiros, e demais participantes, tiveram liberdade para criar as pinturas, a partir do diálogo com o grupo e do conhecimento construído durante o projeto.

Quadro 3 - Ação de extensão de Brito (2017)

\begin{tabular}{|l|l|}
\hline $\begin{array}{l}\text { Nome da ação de } \\
\text { extensão }\end{array}$ & $\begin{array}{l}\text { A Geografia do Tocantins em escola pública da zona rural do } \\
\text { entorno de Araguaína Tocantins }\end{array}$ \\
\hline Coordenador & Eliseu Pereira de Brito \\
\hline Palavras-chaves & $\begin{array}{l}\text { Trocas de saberes e conhecimentos, Vivências, Lugares, Geografia } \\
\text { do Tocantins. }\end{array}$ \\
\hline Proposta & $\begin{array}{l}\text { A proposta Geografia do Tocantins, em escola pública da zona rural } \\
\text { do entorno de Araguaína, Tocantins, tem por objetivo principal criar } \\
\text { um diálogo entre a Universidade Federal do Tocantins, campus de } \\
\text { Araguaína e comunidades rurais. As atividades foram desenvolvidas } \\
\text { em pequenas cidades e povoados próximos a Araguaína, utilizou-se } \\
\text { de oficinas nas escolas com uso de mapas e atividades } \\
\text { participativas. A orientação do diálogo com a comunidade escolar foi } \\
\text { por meio de uma troca de saberes e conhecimento entre } \\
\text { acadêmicos e comunidades. A orientação das atividades foi pelo } \\
\text { Diagnóstico Rural Participativo - DRP em Verdejo (2006), enquanto } \\
\text { pesquisa participativa, com aplicação das técnicas do diagrama de } \\
\text { vem, mapas falados, entre outros. Uma forma de registro foi por meio } \\
\text { de desenhos dos estudantes e transcrição dos diálogos. A proposta } \\
\text { visa uma maior aproximação do curso de Geografia com a }\end{array}$ \\
\hline
\end{tabular}


\begin{tabular}{|l|l|}
\hline & $\begin{array}{l}\text { lomunidade e aperfeiçoar as práticas docentes dos futuros } \\
\text { licenciados em geografia da UFT. }\end{array}$ \\
\hline Fonte: Dados da pesquisa, sistematizados a partir das informações do SIGproj (2018). (grifo nosso)
\end{tabular}

A ação de extensão "A Geografia do Tocantins em escola pública da zona rural do entorno de Araguaína Tocantins", coordenado por Eliseu de Brito, surge da necessidade do docente de traspor os muros da universidade, dando mais sentido às suas aulas de Geografia do Tocantins, bem como inserir a UFT em seu contexto regional.

O projeto realiza oficinas de cartografia, palestras nas escolas rurais, no entorno de Araguaína e em comunidades rurais. O docente divide as atividades do projeto em três momentos, o primeiro é o de concepção do trabalho, que acontece no Grupo de Estudos Geográficos da Amazônia e Tocantins (GEGATO), e também é o momento de avaliação das atividades, isto é, o que deu certo e o que precisa melhorar. O segundo é quando acontece o contato com as escolas ou comunidades, criando um panorama dos locais das ações, feito com o diretor (a) da escola e com representantes da comunidade. O terceiro é o momento da ação, quando é discutida a Geografia do Tocantins, com as oficinas, uso de maquetes. O grupo também recebe as demandas das escolas ou das comunidades, como foi o caso da solicitação de um parecer sobre a viabilidade da criação de um parque turístico, para uso sustentável, por meio do ecoturismo, e da agricultura familiar na comunidade "Amigos da Terra".

A ação de Brito (2017) também está alinhada aos princípios da Resolução da UFT 08/2018, pois as ações foram voltadas ao "impacto social e transformação de forma a estabelecer relação entre a UFT e os demais segmentos da sociedade por meio de uma ação transformadora com ênfase na formação acadêmica e nas demandas da sociedade" (UFT, 2018, n. p.).

Nesse sentido, Freire (2015, p. 211) nos lembra da importância da universidade dialogar com a cidade e sua zona de influência no sentido de "[...] diminuir a distância entre a universidade ou o que se faz nela e as classes populares [...]," para tal "[...] é preciso que a universidade, se ainda não é, vá se tornando uma criação da cidade, estendendo, aos poucos, sua influência à zona em que a cidade se insere".

Observamos que as participações se efetivaram nas ações analisadas com a inserção dos seguintes atores sociais: agentes da CPT, acadêmicos, camponeses 
do Quilombo Grotão, docentes da universidade, grafiteiros, servidores técnicoadministrativos estudantes da Educação Básica, professores das escolas rurais e de pequenas cidades, moradores de povoados e de comunidades rurais.

\section{APRENDIZAGEM COLABORATIVA ENTRE AUTORES E ATORES: a transformação social pela extensão}

A partir da aprendizagem colaborativa entre autores e atores, bem como do reconhecimento da pluralidade de saberes e experiências, a universidade é capaz de ampliar o processo de construção de conhecimentos relevantes socialmente, reconhecendo a participação daqueles que estão fora da academia, não apenas como receptores dos conhecimentos, mas também como coprodutores no processo de construção dos saberes.

Para compreendermos como as ações de extensão articularam o diálogo entre os saberes, por meio das diretrizes das metodologias participativas, incluímos neste artigo entrevistas dos coordenadores das ações. Com esse objetivo, foram feitos contatos com os/as docentes, responsáveis pelas ações selecionados, que foram bem receptivos e se disponibilizaram em colaborar na pesquisa.

Em uma perspectiva de conhecer o desenvolvimento das ações de extensão, fizemos a transcrição e análise das entrevistas, destacando aspectos que interessam às discussões aqui apresentadas. Em relação à discussão de partes das entrevistas, Duarte (2004) afirma que:

\footnotetext{
Entrevistas bem realizadas, com um número adequado de informantes, produzem uma imensa "massa" de informações que não pode nem deve ser tomada como um todo. Do conjunto do material generosamente oferecido a nós pelos nossos informantes, só nos interessa aquilo que está diretamente relacionado aos objetivos da nossa pesquisa [...] e é isso que deverá ser objeto de leitura. (p. 218-219)
}

Ramos Junior (2018) nos explicou os fundamentos que orientaram o seu projeto de extensão, sobre questões agroecológicas, com destaque para: 1) a presença no interior da universidade ou a presença de comunidades que antes estavam menos visíveis; 2) o contato com pesquisadores no pós-doutorado que trabalhavam metodologias participativas de pesquisa; 3) sua experiência pessoal com a teoria da decolonialidade.

Quando o PPGCult abre, a gente começa a querer, até por uma demanda que surgiu muito com a presença da professora Kênia Costa, que já tinha uma experiência com o trabalho da diversidade [...]. Em 2016 apareceu um edital de agroecologia do CNPQ, mandei e-mail para o Felipe da CPT 
[Comissão Pastoral da Terra], como sempre mando para outras pessoas, mas muitas vezes não respondem. Ele respondeu que sim, já tínhamos feito uma conversa antes, ele já trabalhava com isso em outras comunidades. [...] Como eu já trabalhava desde o pós-doutorado com a decolonialidade e as epistemologias do sul, meu olhar já estava voltado pra isso, vi a chance de se materializar nesse projeto. [...] o projeto apareceu como uma oportunidade, demandas, por exemplo: fortalecimento da comunidade na terra, emprego para a juventude [...].

Ao narrar parte da gênese de seu projeto, Ramos Júnior (2009) chama a atenção para as demandas advindas das comunidades. Assim, conforme apontou o trabalho de Sousa (2010), na história da extensão parece-nos que aprimorar sua clareza conceitual se faz necessário e urgente, para que se possa avançar em direção ao seu papel no compromisso da universidade com a sociedade. De maneira semelhante, Paula (2013, p. 6) reconhece as dificuldades conceituais e práticas da extensão e atribui principalmente ao seu caráter interdisciplinar, o que exige da comunidade acadêmica uma nova postura, pois:

a extensão universitária é o que permanente e sistematicamente convoca a universidade para o aprofundamento de seu papel como instituição comprometida com a transformação social, que aproxima a produção e a transmissão de conhecimento de seus efetivos destinatários, cuidando de corrigir, nesse processo, as interdições e bloqueios, que fazem com que seja assimétrica e desigual a apropriação social do conhecimento, das ciências, das tecnologias. (Ibid., p. 6).

Sobre esses processos de apropriação de conhecimentos, via extensão, Brito (2018) afirmou que seu projeto provou mudanças para ele e para os acadêmicos, a partir da experiência com metodologias de pesquisa que priorizam o diálogo com outros saberes:

\begin{abstract}
[...] eu observei com os alunos, um primeiro momento, uma facilidade depois para dialogar com os próprios colegas, eles começam a ter uma abertura melhor para dialogar, eles começaram a entender que as comunidades também eram possuidoras de conhecimentos e saberes e que esses saberes de fato são necessários para que a gente, de fato, possa construir novas formas de se pensar a sociedade tocantinense; é com eles que está parte dos saberes e dos conhecimentos. Então, eles começaram a conseguir construir pontes para entender que as comunidades também são possuidoras de conhecimentos, que são importantes para 0 desenvolvimento cientifico, para o debate da academia.[...] Aproximar os alunos e zona rural, mostrando que o contexto da universidade também é um contexto possível, ou seja, a universidade pública no Brasil ainda é acessível a todos. Então, a gente tem acessibilidade, a universidade também está no contexto deles.
\end{abstract}

Observamos na entrevista de Brito que ele reconhece os saberes da comunidade como importantes. Sobre a relação do saber científico e saber popular, Brandão (2017) afirma ser difícil saber ao certo quando aconteceu a divisão social 
desses saberes, ao esclarecer que: "Não existiu primeiro um saber científico, tecnológico, artístico ou religioso 'sábio e erudito' que, levado a escravos, servos, camponeses e pequenos artesãos, tornou-se, empobrecido, um 'saber do povo'" (Ibid., p. 15). Ao invés disso, afirma que "[...] houve primeiro um saber de todos", sendo esse "[...] separado e interdito, tornou-se 'sábio e erudito'; o saber legítimo que pronuncia a verdade e que, por oposição, estabelece como 'popular' o saber do consenso de onde se originou". O autor continua argumentando que:

\begin{abstract}
A diferença fundamental entre um e outro não está tanto em graus de qualidade. Está no fato de que um, "erudito", tornou-se uma forma própria, centralizada e legítima de conhecimento associado a diferentes instâncias de poder, enquanto o outro, "popular", restou difuso - não centralizado em uma agência de especialistas ou em um polo separado de poder - no interior da vida subalterna da sociedade. (p. 15).
\end{abstract}

A universidade desenvolve um papel fundamental na inclusão social pela educação, quando produz práticas libertadoras e emancipatórias que considerem a complexidade da sociedade evitando, assim, a institucionalização da exclusão dos indivíduos. Nessa perspectiva inclusiva, Testa (2018) explicou a gênese do projeto "Grafite: arte democrática":

\begin{abstract}
Antes de realizar o grafite, que foi feito de modo coletivo, colaborativo, aberto a todos que quisessem e tivessem interesse em participar, em conhecer a técnica do grafite, nós fizemos pela manhã um encontro com esses artistas, teve até xilogravura, que é uma arte na madeira que depois passa um molde e você tem um negativo que sai o trabalho. Então, eles trouxeram alguns de seus trabalhos para expor e apresentar para os acadêmicos, professores e pessoas da comunidade que estavam aqui. $\mathrm{O}$ convite foi aberto a todos, aí nessa exposição eles falaram do processo de criação deles, e do que era o grafite, explicaram a técnica, de onde surgiu, como seguiu, então foi um momento muito especial para que envolvesse todos os participantes. Foi uma prévia, foi um envolvimento para que lá no processo as pessoas já tivessem bem integradas e por dentro do [...] grafite de arte, de fazer uma coisa colaborativa. [...] a gente ofereceu pincéis, os rolos [...] então teve todo um momento de compartilhar esse processo de criação.
\end{abstract}

Segundo Testa (2018), o próprio título do projeto foi uma sugestão dos grafiteiros e que, da mesma forma, aconteceu a escolha dos desenhos, que foram decididos no momento das pinturas pelos artistas e os demais participantes. Nesse processo de negociação entre os envolvidos no projeto, para a docente Testa (2018), as ações coletivas mudam o olhar em relação ao outro:

[...] eu acho que muda a visão dos participantes, mostrando que é possível você desenvolver alguma coisa diferente dentro da universidade, de forma coletiva e colaborativa. Eu acho que essa ideia do colaborativo é o que engrandece as nossas ações, porque uma coisa é você fazer uma ação individual, sozinha, outra coisa é você envolver um maior número de 
pessoas, e mostrar a elas possibilidades de ações coletivas, isso é muito transformador [...]. Esses caminhos mudam nossas relações de sujeitos, a gente passa a olhar o outro mais de perto, passa a vivenciar juntamente com o outro, acho que isso faz o indivíduo crescer.

A afirmação de Testa (2018) nos aproxima dos escritos de Freire (2017b), ao afirmar que os homens são seres da práxis, por isso mesmo, diferente dos demais animais, não são determinados pela História, pois são seres de transformação. Assim, a verdadeira revolução só se dará pelo diálogo, transformando realidades que desumanizam os sujeitos. $O$ autor alertou que seria ingenuidade acreditar que as elites opressoras estivessem comprometidas com uma educação libertadora e, para isso defendeu o diálogo como condição fundamental para libertação, sendo que esse "[...] encontro dos homens para a 'pronúncia' do mundo, é uma condição fundamental para sua real humanização" (FREIRE, 2017b, p. 185). Nessa perspectiva, também acreditamos que a educação universitária é um ato político, uma forma de intervenção no mundo.

O professor Ramos Júnior (2018), coordenador do projeto NEUZA, reconhece a importância das metodologias participativas para se fazer ensino, pesquisa, extensão e produção de culturas, nesse sentido:

As metodologias qualitativas [ou participativas] possibilitam que a extensão se transforme em pesquisa [...]. E a extensão é modo de furar essas barreiras da universidade para se identificar com a população daqui, e a população daqui se identificar com a universidade. É a extensão que vai fazer isso, as metodologias qualitativas ou participativas vão fazer com que a universidade cumpra seus três papéis: o ensino, a extensão, também como formação e monte de outras coisas, e vai virar pesquisa.

Sob este prisma, para Brandão (2018, p. 370):

A relação tradicional e padrão do tipo: sujeito-objeto, entre investigadoreducador e os grupos populares, deve ser progressivamente convertida em uma relação do tipo sujeito-sujeito, a partir do suposto de que todas as pessoas e todas as culturas são fontes originais de seus sentidos e saberes. Deve partir ainda da consciência de que é desde a interação entre os diferentes conhecimentos que de forma partilhável de compreensão da realidade poderá ser construída através do exercício de uma pesquisa participante. Os saberes científicos e os saberes populares articulam-se criticamente em um outro conhecimento solidariamente compartido, culturalmente inovador e socialmente transformador.

$\mathrm{Na}$ ação de extensão "Construindo Saberes: Agricultura Familiar e Movimento Agroecológico", o caráter participativo foi observado a partir das características da comunidade local. De acordo com o professor Ramos Junior (2019), nas 
comunidades tradicionais no Brasil, existem lógicas internas (específicas de cada grupo social) de quem participa da ação, nesse sentido, segundo o professor, na atividade prática na comunidade Grotão (comunidade quilombola), a liderança da comunidade foi quem selecionou os membros que poderiam participar da ação.

\begin{abstract}
Pelo que eu entendi, da última vez foi assim, o Raimundo [liderança da comunidade] chamou eles, tipo assim: "[...] precisa fazer tal coisa aqui". Inclusive, na última vez precisamos esperar ele chegar para iniciar o plantio [ou seja, sem a presença do Sr. Raimundo não seria possível iniciar a parte prática.]. [...]. Na verdade eu nem tinha pensado nisso, [...] ainda não tinha codificado na minha cabeça, mas é isso.
\end{abstract}

Isso significa que, no desenvolvimento de metodologias de pesquisa participativa, respeitar a organização interna da comunidade é um dos princípios para que se configure uma investigação do povo e com o povo (FREIRE, 2017c). O autor lembra também que realizar ações considerando apenas a visão de mundo de seus idealizadores, por mais bem-intencionadas que possam ser, essas não terão efetividade na prática, ou seja, não promoverão mudanças.

$\mathrm{Na}$ entrevista do docente Brito (2019), também aparecem características semelhantes à ação de Ramos Junior, pois o seu contato com as comunidades foi feito por meio das lideranças locais, que se encarregaram de organizar as reuniões com seu grupo de pesquisa e explica que "a liderança da comunidade é a pessoa que a gente contata lá, essa pessoa organiza o público [que participará da ação]". Pelas narrativas dos nossos interlocutores, observamos que a dimensão da participação deve ser qualitativa pois, quantitativamente, um número pequeno está envolvido na ação, mas já é o suficiente para que sejam multiplicadores em seus contextos e garantam a perenidade da ação, mesmo ao final de um projeto de extensão institucionalizado.

Assim, nas entrevistas dos docentes, coordenadores dos projetos de extensão, foram evidenciadas as possibilidades de transformação social pela ação da universidade, representada pelos projetos de extensão, em aproximar a universidade dos sujeitos sociais que, até então, não se viam encorajados a participarem de ações em parceria com o ensino superior. 


\title{
5 DIÁLOGOS POSSÍVEIS ENTRE UNIVERSIDADE E SOCIEDADE: desafios e
} possibilidades

Conforme temos afirmado, a extensão universitária está ancorada no princípio da indissociabilidade entre ensino e pesquisa, e essa é "[...] um processo interdisciplinar, educativo, cultural, científico, político e tecnológico que promove a interação transformadora entre universidade e outros setores da sociedade [...]" (UFT, 2018, n. p.). Logo, identificamos esse sentido dado às ações, nas entrevistas dos docentes e, para exemplificar, de acordo com Ramos Júnior (2019):

Acho que a extensão é esse lugar... Em outro projeto de extensão [coordenado por ele] vieram muitos alunos para a universidade ou gente que estava afastada e retornou, a extensão que vai dizer: a porta é essa. Essas ações que nós e outros professores têm feito, elas furam barreiras. Esses estudantes estão vindo [...] pois em outros trabalhos anteriores, com um grupo de três professores, desses trabalhos resultaram a vinda à universidade de umas trinta pessoas que não estudavam aqui. Mesmo alunos que moram perto da universidade [...] não procuravam aqui para estudar, acredito que conseguimos dizer a eles que aqui era também lugar para eles e hoje são acadêmicos da graduação e pós-graduação.

O docente Brito (2019) lembra que sua ação de extensão motivou alguns alunos para cursar Geografia, do qual o docente é professor titular, além disso, ressalta a importância de as turmas entenderem a aplicabilidade dos conhecimentos acadêmicos:

\begin{abstract}
Muitos dessas comunidades, acredito que uns oito alunos, vieram para a universidade, acredito que seja uma forma de se levar o curso também. [...] Acho que mostra que o curso tem aplicação no planejamento e ensino da Geografia, uma formação de professores que se está buscando; formar professores que possam atender esse contexto rural e regional. Acho que é um dos objetivos é mostrar [...] os desafios contexto regional. Que esses jovens podem entrar na universidade, que podem concluir um curso superior, abrir novas portas de trabalho. Não levo só a Geografia do Tocantins para essas comunidades, levo a UFT como possiblidade.
\end{abstract}

$\mathrm{Na}$ ação coordenada por Brito (2018), o potencial de transformação social também pode ser observado quando uma comunidade convida seu grupo para fazer um parecer de como uma área, dentro do assentamento, que poderia ser ocupado por atividades econômico-turísticas, por meio da criação de um parque turístico, na região conhecida como Vão do Canto Grande (região localizada entre Darcinópolis e Ananás- Tocantins, há $105 \mathrm{~km}$ de Araguaína). Nesse sentido, o grupo fez um mapeamento dessa região como ponto turístico, por meio de fotos, e foi discutido em duas escolas, uma no assentamento outra na cidade, e também na comunidade rural. As fotos da região foram apresentadas como parte de um contexto maior que 
foi a Geografia do Tocantins em sua diversidade de paisagem. Também aconteceu um diálogo entre o Grupo de Estudos Geográficos da Amazônia e Tocantins (GEGATO) e a comunidade, em que foram discutidas alternativas.

Na reunião sobre o parque eles falaram: estamos precisando disso, vocês estão entendendo assim, mas o que é mesmo atrativo é do outro lado, não é aqui, precisamos revisar o outro lado, foi quando falaram das cachoeiras. Quando você está em campo as coisas se adequam, não costumo levar para pesquisa perguntas pré-estabelecidas. [...] Nós estamos formatando a cartilha do Vão do Canto Grande, já foi uma via para a comunidade que retornou com correções na cartilha, colocando também o que eles queriam.

Streck (2016) lembra-se da necessidade da praticabilidade do conhecimento,

tanto em pesquisas qualitativas como em metodologias participativas, isto é, quando o conhecimento gerado poder ser útil tanto para a comunidade científica como para a comunidade:

Uso o termo praticabilidade para distinguir o conhecimento produzido na pesquisa participante tanto da pesquisa aplicada, que gera o conhecimento para, então, aplicar ou "transferir" para a prática, quanto de praticidade, que tem uma conotação de comodidade e adaptação. Praticabilidade refere-se à possibilidade de retroalimentar a prática no processo de pesquisa para, assim, gerar uma teoria mais coerente com a prática. [...] A pesquisa de que tratamos propõe-se a ser útil, não no sentido de um utilitarismo estreito, mas de contribuir tanto para o campo da prática, quanto para a comunidade científica. (STRECK, 2016, p. 544).

Nesse sentido, para a docente Testa (2018), o Projeto Grafite contribuiu para maior contato dos acadêmicos do câmpus com arte e, consequentemente, mudanças nas maneiras de enxergar as diferenças humanas.

\begin{abstract}
A visitação do espaço grafite que ficou bem localizada [em alguns muros da universidade]. Todo mundo tira foto no espaço, agrega porque afeta o espaço e a relação do espaço com as pessoas, primeiramente porque munda da cara do Câmpus universitário porque você dá outra possibilidade das pessoas se sensibilizarem diante da arte, afeta o espaço, muda o olhar do acadêmico. Essa sensibilização para a arte já é uma mudança de paradigma, de postura, de olhar. Você traz a arte para dentro da universidade, as pessoas querem estar presentes juntos da criação. Virou pesquisas também [outro professor está também pesquisando o assunto], estudos, artigos, os desdobramentos podem gerar outras coisas, que até eu desconheço. São coisas que podem ter surgido a partir dessas imagens do grafite, [...] dar oportunidade para o aluno de ter um olhar mais sensível voltado para arte.
\end{abstract}

Conforme argumenta Brandão (2006, p. 13), "uma pesquisa é também uma pedagogia que entrelaça atores-autores e que é um aprendizado no qual, mesmo quando haja diferenças essenciais de saberes, todos aprendem uns com os outros e através dos outros". Assim, Streck e Adams (2014, p. 50) nos lembram de que:

[...] o contexto da pesquisa não é uma instância fixa e inerte à espera da ação dos pesquisadores, mas é configurado no processo de pesquisa. A dinâmica investigativa vai identificando novos campos e outros nexos, que 
fazem com que o contexto se modifique constantemente, ora se ampliando, ora exigindo um olhar focado em detalhes.

Sobre essa dinâmica investigativa, o professor Ramos Junior (2019) fez uma análise crítica da sua ação extensionista, pois, até o momento da entrevista, do ponto de vista do plantio agroecológico, os resultados foram mínimos, porém do ponto de vista qualitativo se evidencia ganhos interessantes, como a valorização dos saberes tradicionais. Nesse sentido, o professor acredita que tenha alcançado mais ganhos formativos.

\begin{abstract}
Já têm resultados qualitativos muito interessantes, por exemplo: quando a gente tem uma quilombola dentro do grupo [NEUZA] e ela fica "obrigada", como parte da pesquisa dela, a fazer o levantamento dos saberes tradicionais agrícolas da comunidade e ela começa a perguntar isso [dentro da comunidade], isso aproxima os jovens dos idosos, dessa tradição, que é sempre um problema nas comunidades. É sempre a reclamação de que os jovens estão abandonando [a comunidade], porque têm as facilidades que 0 mundo moderno traz. Então, você já tem uns resultados qualitativos muito interessantes, cria-se a ideia assim: "ah agroecologia, nosso jeito de produzir tá certo". Lógico que queremos resultados também práticos, nosso maior objetivo é a construção da comunidade prática: que é essa comunicação entre a universidade e comunidades. [...] Dentro da comunidade acadêmica o impacto também tem sido grande, já tem monografia sobre o quilombo, dissertação sobre outra comunidade onde a agroecologia está bem avançada. São ganhos, mas que eu chamaria de formativos.
\end{abstract}

Ramos Junior (2019) relata que houve dificuldades enfrentadas na realização da ação, desde problemas dentro do próprio grupo de trabalho até questões relacionadas ao tempo de realização dessas atividades de caráter participativo, e que não é possível fazer ações emancipatórias em curto prazo.

\footnotetext{
Nas nossas mais doces esperanças de fazer participativo... nossas diplomacias todas, a gente não imaginava que ia enfrentar os problemas que a gente enfrentou. A gente sabia que ia ter dificuldades, mas a gente imaginava que seriam outras, não as que acabaram acontecendo. A gente está tentando ir para cá, mas as estruturas, as relações acabam levando a gente pra lá [outro lado]. Então... no limite esse trabalho de dois anos, se ele durar só dois anos, eu não sei o que ele vai deixar de duradouro para as comunidades. Não pode durar só dois anos, é pouco tempo. Você tem que continuar, não tem nada de curto prazo. Você pode até publicar o livro sobre a comunidade, que a gente vai fazer, o mapa que já estamos fazendo, o Vinicius [docente de Geografia que participa do núcleo] está terminado, estamos pensando em comprar um drone para melhorar o mapeamento. Então a gente pode fazer um monte de coisas, mas do ponto de vista da formação e da construção de uma comunidade agroecológica, isso é um trabalho de médio prazo. Então, o projeto de extensão ele não pode ser como algo (...) imediato, [pois] é um projeto de formação.
} 
Nessa perspectiva de formação, para Brandão e Streck (2006, p. 273), o método se insere no complexo movimento da teia da pesquisa, se assim não fosse, "[...] uma vez dominado determinado processo, teríamos a chave mágica para a realidade". Pelo contrário, "o método vai se reconfigurando constantemente no diálogo com e entre os fatores. Na imagem de Mário Quintana, são os passos que fazem o caminho" (p. 273).

A pesquisa participante oferece múltiplas possibilidades para o diálogo e a interação, promovendo múltiplas capacidades e co-gerando novos saberes, o que Giatti (2020) chama de "ecologizar os saberes". Segundo Giatti (2020, p. 126, tradução nossa), "intersubjetividade, confiança, poder de compartilhamento e reciprocidade legítima fornecem interação simétrica, e em tal terreno é possível associar a mobilização de diferentes atores sociais em uma ação convergente".

Para Brito (2019), dentre os desafios de realizar atividades de extensão está em conseguir atender as expectativas da comunidade externa, em fazer com que a universidade possa ser uma possibilidade real para essas comunidades, mas o docente compreende sua responsabilidade ao fazer essa aproximação:

Uma das grandes dificuldades que enfrentei foi dar a cara, na extensão
você sai de área de segurança e vai para comunidade dar a cara, discutir
com ela, muitas vezes você é cobrado. [...] muitas vezes a plano de
necessidade da comunidade não corresponde ao meu tempo da
universidade, gera uma expectativa. A extensão tem essa dificuldade por
gerar expectativa quando você leva a universidade [...] meu maior desafio é
não levar frustações [prometer coisas e não conseguir cumprir], levar
possibilidades, procuro levar esperança.

Chauí (2001, p. 119) lembra que nas regiões Norte e Nordeste do Brasil a compatibilidade das duas vocações da universidade, a científica, e a política tendem a serem mais presentes, uma vez que o Estado "[...] é quase a única força econômica, social e política existentes [...]". Porém, alerta para a necessidade da iniciativa da promoção da compatibilidade ser da própria universidade, a partir de politicas institucionais, caso contrário, essas ações ficariam conhecidas como "[...] ação fortuita do Estado ou como carreira individual e pessoal de alguns quadros universitários".

Nesse sentido, a UFT é uma das poucas universidades públicas do estado do Tocantins, que está localizada na região norte do Brasil, como tal tem grande oportunidade de promover essa articulação. Deste modo, entendemos que os projetos institucionais e as ações extensionistas universitárias serão mais pertinentes e relevantes à sociedade, quando amparadas por metodologias que 
efetivem a participação de todos os envolvidos no processo, de forma horizontal, visando uma ação educativa para a prática da liberdade. Esse comprometimento no/com o processo extensionista deve ser de todos que compõem a universidade, comprometidos com a sua função social.

A partir das entrevistas analisadas, percebemos que os coordenadores dos projetos selecionados para esta pesquisa, apresentaram uma postura de respeito aos saberes "não-acadêmicos" e que valorizam a dimensão extensionista da universidade. Esses profissionais avaliaram como esses projetos foram importantes para sua atividade docente, como, por exemplo, as mudanças de postura na sala de aula e na formação dos seus acadêmicos. Por isso, acreditamos na educação problematizadora, defendida por Freire, isto é, no diálogo, em que "o pensar do educador somente ganha autenticidade na autenticidade do pensar dos educandos, mediatizados ambos pela realidade, portanto, na intercomunicação" (FREIRE, 2017c, p. 89).

Ao analisar os documentos institucionais, podemos destacar que a proposta de extensão da UFT apresenta um caráter dialógico, educativo comprometido, o que inspirou no desenvolvimento de projetos que valorizaram as interlocuções com a sociedade, por meio das trocas de saberes.

É importante ressaltar que, embora exista um espaço institucional para experiências que valorizem a extensão de modo participativo, na prática essas ações encontram dificuldades, dentre as quais podemos destacar: a institucionalização deste tipo de experiência ainda está em construção, pois fica muito centrada na figura do docente que realiza ou do grupo de pesquisa que compõe; pouca compreensão de alguns docentes do que realmente significa extensão universitária, isto é, a própria lógica do conceito, pois algumas atividades destinadas apenas para a comunidade acadêmica interna são cadastradas como extensão; e a pouca experiência da universidade nesse tipo de ação, tendo em vista que a UFT tem apenas 16 anos de existência.

Essa relação dos professores da universidade, com movimentos sociais, artistas de rua, acadêmicos, comunidades tradicionais e docentes da educação básica, reforça a concepção freireana de que o conhecimento é fruto de uma relação educador-educando, por meio do compartilhamento dialógico de saber. 
extensão de conhecimentos técnicos; não é o ato de depositar informes ou fatos nos educandos; não é a "perpetuação dos valores de uma cultura dada"; não é "o esforço de adaptação do educando a seu meio'. Para nós a "educação como prática da liberdade" é, sobretudo e antes de tudo, uma situação verdadeiramente gnosiológica. (FREIRE, 2017a, p. 104).

A situação gnosiológica é "aquela em que o ato cognoscente não termina no objeto cognoscível, visto que se comunica a outros sujeitos, igualmente cognoscente (Ibid., p. 104)." Para Buofleuer (2018, p. 240-241), a situação gnosiológica de Freire,

[...] sugere que a verdadeira cognoscibilidade é coparticipada, porque não conhecemos de modo absolutamente isolado, já que, de alguma forma, sempre dialogamos com quem nos precedeu na cultura e com aqueles que compartilham conosco o tempo presente. Uma autêntica situação gnosiológica, portanto, requer o desejo de aprender sempre de novo, com cada novo interlocutor e com cada nova situação.

Mediante tais considerações, entendemos que ações de extensão participativas apontam para um caminho a ser percorrido pela universidade, em busca de maior diálogo com a sociedade. Nesse sentido, estamos de acordo com Paula (2013, p. 18), "[...] trata-se, essencialmente, de ver a extensão universitária como uma cultura, como uma prática, como um compromisso, indispensáveis à plena realização da universidade como instrumento emancipatório".

\section{CONSIDERAÇÕES FINAIS}

A partir do olhar teórico de diferentes áreas do conhecimento, buscamos empreender o debate sobre a extensão universitária como espaço de interação, encontro e socialização de conhecimentos. As metodologias participativas de pesquisa foram inspiradoras para os três docentes construírem novos espaços de diálogo, pensando que homens e mulheres são seres de relação e que a aprendizagem acontece nesse espaço de inter-relação. Nessa perspectiva, as metodologias participativas demonstraram ser esse espaço democrático, que possibilita o protagonismo de todos os sujeitos envolvidos no processo, promovendo assim, mediações horizontais e colaborativas entre os saberes.

Porém, apesar do espaço institucional e de algumas práticas por parte de alguns docentes, a extensão ainda tem dificuldade de se efetivar de forma participativa e emancipatória, o que nos leva a definir esse novo momento da extensão universitária no Brasil, como um processo em construção, que anseia por uma extensão dialógica e comprometida com as culturas locais.

Verificamos também que, para muitos docentes, a lógica do conceito de extensão universitária, ainda não é bem compreendida, quando observamos que 
muitos projetos cadastrados no SIGProj são de interesse explicitamente de acadêmicos (comunidade universitária interna), mas que são cadastradas como ações de extensão, que implicaria a participação da comunidade externa à universidade também. Em outras palavras, a concepção de extensão se descaracteriza quando apenas o público interno à universidade participa das ações planejadas.

Temos a convicção de que o campo extensionista pode ofertar grandes contribuições, principalmente, ao passo que a universidade se reconheça como parte da solução para a inclusão social, por meio da educação. Por meio desta pesquisa, concluímos que a extensão universitária é um caminho viável, capaz de promover mudanças no paradigma do saber acadêmico e no reposicionamento dos docentes frente à realidade local e ao "outro", deixando de ser considerada, na maioria das vezes, como mero complemento, um apêndice.

Nas ações de extensão pesquisadas, a partir dessa prática criadora, foi possível que sujeitos visualizassem a universidade como algo mais próximo e possível. Ficou evidente que as metodologias participativas de pesquisa são caminhos teórico-metodológicos para a universidade se aproximar da comunidade, pois só assim poderemos conhecer, de fato, quais são suas ideias, preocupações, interesses e demandas, pontos de partida para a proposição de ações pertinentes, relevantes e equitativas. Por fim, acreditamos no papel transformador da educação e na formação de profissionais capazes de conhecer seu contexto histórico, político, cultural e, principalmente, buscar a ressignificação da relação universidade e sociedade.

A partir desta pesquisa, observamos a necessidade de estudos futuros, que possam investigar outras vertentes de como as ações extensionistas podem encorajar a sociedade a ver a universidade como parte da solução, isto é, reconhecer que por meio da integração dos docentes, estudantes e comunidade possa ser construída a superação de possíveis preconceitos, em busca de (re)construir nossos olhares, conceitos, práticas e atitudes frente ao diferente. 


\section{REFERÊNCIAS}

BOUFLEUER, José Pedro. Gnosiológico (situação). In: STRECK, D. R.; REDIN, E.; ZITKOSKI, J. J (Orgs.). Dicionário Paulo Freire. 4. ed. rev. amp. Belo Horizonte: Autêntica, 2018. p. 240-241.

BRANDÃO, Carlos Rodrigues.; STRECK Danilo R. (Orgs.). Pesquisa Participante: a partilha do saber. Aparecida SP: Ideias \& Letras, 2006.

. O que é educação popular. eBook. São Paulo: Brasiliense, 2017.

; REDIN, E. ; ZITKOSKI, J. J (Orgs.). Dicionário Paulo Freire. 4. ed. rev. amp. Belo Horizonte: Autêntica, 2018.

BRASIL. Constituição (1988). Constituição da República Federativa do Brasil: 1988. Brasília, DF: Câmara dos Deputados, 2005. 437 p. Disponível em: http://www.stf.jus.br/arquivo/cms/legislacaoConstituicao/anexo/CF.pdf. Acesso em: 20 jun. 2018.

. Lei no 9394, 20 de dezembro de 1996. Institui a Lei de Diretrizes e Bases da Educação Nacional. Disponível em:

http://www2.senado.leg.br/bdsf/bitstream/handle/id/529732/lei_de_diretrizes_e_base s_1ed.pdf. Acesso em: 20 jun. 2018.

CHAUÍ, Marilena de Souza. A universidade pública sob nova perspectiva. Revista Brasileira de Educação. 2003, n. 24, p. 5-15. Disponível em:

http://www.scielo.br/pdf/rbedu/n24/n24a02.pdf. Acesso em: 20 abr. 2018.

Escritos sobre universidade. São Paulo: Editora da UNESP, 2001.

DUARTE, Rosália. Entrevistas em pesquisas qualitativas. Educar. Curitiba. 2004, n. 24, p. 213-225. Disponível em: http://www.scielo.br/scielo.php?pid=S010440602004000200011\&script=sci_abstract\&tIng=pt . Acesso em: 20 out. 2018

FREIRE, Paulo. Cartas a Cristina: reflexões sobre minha vida e minha práxis. Organização e notas de Ana Maria Araújo Freire. 2. ed. São Paulo: Paz e Terra, 2015.

Extensão ou Comunicação? Tradução Rosiska Darcy de Oliveira. 18. ed. Rio de Janeiro/São Paulo: Paz e Terra, 2017a.

. Pedagogia da Autonomia: saberes necessários à prática educativa. 55. ed. Rio de Janeiro/ São Paulo: Paz e Terra, 2017b.

Pedagogia do Oprimido. 64르 ed. Rio de Janeiro/ São Paulo: Paz e Terra, 2017c.

Pedagogia da Esperança: um reencontro com a Pedagogia do Oprimido. 24. ed. São Paulo/Rio de Janeiro: Paz e Terra, 2018.

GIATTI, Leandro, Luis. Participatory Research in the Post-Normal Age. Unsustainability and Uncertainties to Rethink Paulo Freire's Pedagogy of the Oppressed. Cham: Springer, 2020.

GUTBERLET, Jutta ; PONTUSCHKA, Nidia, Nacib. Pesquisa qualitativa sobre consumo: experiências interdisciplinares. Olhar do professor. Ponta Grossa, v.13, p. 217-224, 2010. 
HALL, Stuart. Cultura e representações. Organização e Revisão Técnica: Arthur Ituassu. Tradução: Daniel Miranda e William Oliveira. Rio de Janeiro: Ed. PUC-Rio: Apicuri, 2016, 260 p.

PAULA, João Antônio de. A extensão universitária: história, conceito e propostas. Interfaces - Revista de Extensão, Belo Horizonte, v. 1, n. 1, p. 05-23, jul./nov. 2013. Disponível em:

http://www.dche.ufscar.br/extensao/Aextensouniversitriahistriaconceitoepropostas1.p df. Acesso em 15 fev. 2019.

POMBO, Olga. Interdisciplinaridade e integração dos saberes. Liinc em Revista. Porto Alegre, v.1, n. 1, p. 3-15 março, 2005. Disponível em: http://revista.ibict.br/liinc/article/view/3082. Acesso em 24 abr. 2018.

SANTOS, Boaventura de Sousa. A universidade no século XXI: para uma reforma democrática e emancipatória da universidade. 3. ed. São Paulo: Cortez, 2011.

. Boaventura de Sousa Santos destrincha o assédio neoliberal às universidades. [Entrevista concedida] Javier Lorca. Revista IHU ON-LINE, São Leopoldo- RS, 16 Junho 2018.

Sistema de Informação e Gestão de Projetos (SIGProj). Disponível em: http://sigproj1.mec.gov.br/. Acesso em: 08 mar. 2018.

SOUSA, Ana Luiza Lima. A história da extensão universitária. $2^{\underline{a}}$ ed. Campinas: Alínea, 2010.

STRECK, Danilo R.; ADAMS Telmo. Pesquisa Participante, emancipação e (des) colonialidade. Curitiba- PR: CRV, 2014.

. Metodologias participativas de pesquisa e educação popular: reflexões sobre critérios de qualidade. Interfaces. 2016, vol. 20 n. 58, p. 537-547.

Universidade Federal do Tocantins (UFT). Pró-Reitoria de Extensão, Cultura e Assuntos Comunitários (Proex).

Resolução oㅡ 08 de 14 de março de 2018. Dispõe sobre o Regulamento das Ações de Extensão da Universidade Federal do Tocantins. Disponível em: https://docs.uft.edu.br/share/s/Y38nXIY2QN61ReEWR2778Q. Acesso em: 02 out. 2018. 